\title{
Çocuk Oyunları ve Oyunların Bireylerin Gelişimine Katkısı (Mardin Çocuk Oyunları Örneği)
}

\section{Kids Games and Contribution of Games to the Development of Individuals (Example of Mardin Children's Games)}

\author{
Erhan Akın ${ }^{\text {a,* }}$, Serhat Kıztanr ${ }^{\text {b }}$, Deniz Edip ${ }^{c}$ \\ aDDoç. Dr., Siirt Üniversitesi, Eğitim Fakültesi, Türkçe Eğitimi ABD, Siirt/Türkiye. \\ ORCID: 0000-0003-2372-9331 \\ b Siirt Üniversitesi, Sosyal Bilimler Enstitüsü, Türkçe Eğitimi ABD, Yüksek Lisans Öğrencisi, Siirt/Türkiye. \\ ORCID: 0000-0002-7246-9153 \\ ${ }^{c}$ Siirt Üniversitesi, Sosyal Bilimler Enstitüsü, Türkçe Eğitimi ABD, Yüksek Lisans Öğrencisi, Siirt/Türkiye. \\ ORCID: 0000-0001-8480-2390
}

\section{MAKALE BİLGİSİ}

\section{Makale Geçmiși:}

Başvuru tarihi: 2 Kasım 2020

Düzeltme tarihi: 20 Mart 2021

Kabul tarihi: 1 Nisan 2021

Anahtar Kelimeler:

Oyun,

Çocuk,

Mardin,

Çocuk Oyunlarının Gelişime Etkisi
ÖZ

Nitel araştırma türlerinden olan doküman incelemesi ve yarı yapılandırılmış görüşme tekniği kullanılarak yürütülen, Mardin çocuk oyunlarının derlenmesi ve bireylerin gelişimine katkısının amaçlandığı çalışmada; öncelikle Mardin ilinde oynanan çocuk oyunları ile ilgili saha çalıșması yapılarak oyunlar hakkında bilgi derlenmiştir. Bu şekilde kayıt altına alınan yirmi oyun hakkında bilgiler verilerek oyunların bireylerin gelişimine katkısı üzerinde durulmuştur. Çalışma sonucunda oyunların bireylerin fiziksel, zihinsel gelişimine ve dil becerilerine katkıda bulunduğu tespit edilmiştir. Çalışmanın çıkış noktası olan oyunların; çocukları birçok açıdan etkisi altına aldığı, çocukların bütünsel gelişimine katkıda bulunduğu gerçeğini de daha gözler önüne sermektedir. Çalışma eklerinde görüşlerinden yararlanılan ve oyunlar hakkında bilgi veren kaynak kişilere ait bilgiye yer verilmiştir.

\section{ARTICLE INFO}

\section{Article history:}

Received: November 2, 2020

Received in revised form: March 20, 2021 Accepted: April 1, 2021

\footnotetext{
Keywords:

Game,

Child,

Mardin,

The effect of children's games on

development
}

\begin{abstract}
A B S T R A C T
This study was carried out using document analysis and semi-structured interview technique, which were among qualitative research types. The aim is to compile Mardin children's games and for contribution to individual development. Information given about the twenty games recorded in this way, emphasizes the contribution of games the development of individuals. As result of study, it was determined that games contributes the physical and mental development and language skills of individuals. The games that are the starting point the study; It also reveals the fact that it influences children in many ways and contributes to the holistic development of children. The study, information about the source persons' whose opinions were benefited and provided information about the games were included.
\end{abstract}

\section{Giriş}

İnsanoğlu yaratılışından günümüze kadar olan süreçte sürekli üretme ve kendine yeni alanlar açma gayretinde olmuştur. Bilinçli, ya da bilinçsiz bu çabayı hep sürdürmüştür. Kimi zaman canı pahasına da olsa bu çabasını sürdürmüştür. Özellikle sosyal yaşama dönük çabalara bakıldığında kültür başlığı dikkat çekmektedir. Çünkü kültür birçok alanı içinde barındırmaktadır. Ekonomiden sanata, eğlenceden yaşama ait birçok husus kültür kavramı içinde yer almaktadır.

\footnotetext{
*Sorumlu yazar/Corresponding author. e-posta: erhanakin49@hotmail.com
} 
Kültür, nesilden nesile aktarılır ve toplumun bütün bireyleri tarafindan paylaşılmaktadır. Kültür, ait olduğu toplumu birtakım ölçüler içerisine sokarak sınırlamaktadır. Kültür, bir olgunun başka bir olgu tarafindan tanımlanması, simgelenmesi veya kullanılmasıyla alakalıdır (Yeşil, 2013: $55)$.

Kültür; öğrenilir, uyarlanabilir, kuşaktan kuşağa aktarılabilir, paylaşılabilir, sınırlayıcıdır, simgeleyicidir ve birbirini bütünleyen çeşitli unsurlardan oluşur. Kültür, öğrenilerek ve tecrübe edilerek kazanılır ve bunun yanında kültür üzerinde uyarlama yapmak insanın doğal kabiliyeti dâhilindedir (Mutlu, 1999).

$\mathrm{Bu}$ açıdan bakıldığında çocuk oyunlarının da kültürün bir parçası, aktarıcısı, çocukları hayata hazırlayıcı bir etken olarak düşünüldüğünde kültürle yakın ilişkisi göze çarpmakla beraber halk bilimiyle arasındaki münasebet de dikkat çekmektedir. Bu açıdan bakıldığında halk biliminin önemli çalışma alanlarından birisinin de çocuk oyunları olduğu söylenebilir. Çocuk oyunları, halk kültürünün birçok unsurunu ya doğrudan ya da kendi içinde oyun davranışları bünyesinde barındırmakta: dil, inanç, gelenek ve görenekler, ezgiler, değerler, tutum olarak ortaya koymakta ve çocuklarımız, halk kültürünün aktarılmasında önemli bir rol üstlenmektedir (Çolak, 2005: 4-6). Çocuklar, kadınlarla birlikte en önemli kültür taşıyıcıları olarak kabul edilmektedir. Çocuk oyunları, Çocuk oyunlarındaki dil, inanç, gelenek ve görenekler, ezgiler, değerler, tutum ve davranış biçimleri gibi unsurlar, oyunlara ulusal kimlik kazandırır. Sözlü kültür geleneğinin önemli bir parçası olan çocuk oyunları, içinde yaratıldıkları ve icra edildikleri sosyokültürel ortamın aynası durumundadır. Kadınlar ve yaşlılarla birlikte geleneğin en önemli taşıyıcıları çocuklardır (Özdemir, 2006: 17'den aktaran: Çolak, 2005: 31).

Kültürel değerlerin taşıyıcısı olan çocuklarla iletişim kurmanın, onların dünyasını paylaşmanın birçok yolu bulunmaktadır. Oyun, bu yolların en doğal olanı, en sık kullanılanı ve en sağlıklı sonuç vereni olarak kabul edilebilir. Oyun, çocuğun gelişimi için yaşamsal bir önem taşımaktadır. $\mathrm{Bu}$ nedenle oyunla ilgili değişik tanımlara rastlamak mümkündür. Tüm bu tanımlardan hareketle genel olarak oyun; "belli bir amaca yönelik olan ve olmayan kurallı ya da kuralsız gerçekleştirilen fakat her durumda çocuğun isteyerek ve hoşlanarak yer aldığı, fiziksel, bilişsel, dil, duygusal ve sosyal gelişimini temel alan, gerçek hayatın bir parçası ve çocuk için en etkin öğrenme süreci” şeklinde ifade edilmektedir (Dönmez-Baykoç, 1992: 13). Oyunun çocuk için, ciddi bir uğraş; eğlence aracı olduğu bilinmektedir. Dünyanın her yerinde, her çağda ve kültürde çocuklar oyun oynamaktadır. Çocuğun bulunduğu her yerde oyunun bulunması evrensel bir kuraldır. Oyunun evrensel olma özelliği, çocuğun yaşamında beslenme, solunum gibi temel ögelerden biri olmasından kaynaklanmaktadır. Oyun, bilişsel, dil, fiziksel, duygusal ve sosyal gelişim alanlarını desteklemektedir (Erden ve Alisinanoğlu, 2002).

Fink'e (2015) göre oyun, insan hayatının yöresindeki bir kenar fenomen, yalnızca ara sıra ortaya çıkan tesadüfi bir fenomen değildir. Oyun esasen insan varoluşunun ontolojik yapısının bir parçasıdır; hayati öneme sahip temel bir fenomendir.

İnsan uygarlığının, oyun olarak, onun içinde ortaya çıktığı ve geliştiği şeklindeki kanaatim çok eskilerden başlayarak, yavaş yavaş güçlendi (Huizinga, 1995: 69). Çünkü çocukların oyun dünyalarında söz konusu olan oyuncunun gerçek hayatta sahip olduğu kapasitelerin arttırılması değil, şeylerin farklı kapasitelere sahip olduğu bir dünyaya adım atmaktır (Kara, 2014: 14). Zaten Dünyayı bir oyun olarak yorumlar çoğu düşünür. Ve onlar için dünya-oyununun derinliği "dipsiz" bir satranca benzer. Bir oyunun kurallarını biliyorken, nasıl bir oyun oynandı $\breve{g ̆}_{1}$ ise tam olarak anlaşılamaz. Çünkü bir amacı ve sonu olmayan kusursuz bir oyun asla kendini ele vermez. Oyunun kendiliği ve doğallığ1 yalnızca hareketinde gizlidir. Bir oyun sonsuz temsilleri sergiler ve sınırsız olanakları içerir. Bu yüzden kişi oyun oynarken her türlü ihtimale ve tehlikeye hazırlıklı olmalıdır (Dursun, 2014).

Çocukların oyunları, bilişsel ve duygusal ögelerin yanı sıra sosyokültürel boyutlar da taşımaktadır. Dolayısıyla çocukların oyunlarının incelenmesi, oyunların bilişsel ve duygusal boyutlarını anlamamıza yardımcı olabileceği gibi; oyun biçimlerinde anlatım bulan kültürel ögeleri, çocukların toplumsal kimlik ve bağlılıklarını biçimlendirmelerine de yardımcı olan bu oyun etkinliklerine nasıl katıldıklarını anlamamıza da yardım edebilir (Çok, vd., 2004: 17).

Oyun, çocuğun fiziksel, bilişsel, duyuşsal ve sosyal yönden gelişimini sağlayan önemli araçlardan biridir. Çocuğun büyümesi ve sağlıklı bir şekilde gelişmesi için beslenme ve sevgi kadar gereklidir. Çocuk oyun aracılığg ile üzüntülerini, kaygılarını, düşmanlıklarını, sevgilerini, kıskançlıklarını, hayallerini, iç çatışmalarını, düşüncelerini ifade eder (Cirhinlioğlu, 2001: 167-168). Yaşam ile ilgili deneyimleri oyun aracılığı ile öğrenen çocuk, oyun sırasında çeşitli roller üstlenerek dünyayı kendi duyularıyla algılamaya çalışmakta ve büyüdüğünde sürdüreceği uğraşlara, üstleneceği rollere oyun sayesinde hazırlanmaktadır (Anılan vd., 2003: 3). Bu açıdan bakıldığında çocuk oyunlarının çocuğun gelişiminde ne denli önemli olduğu gözden kaçırılmamalı, çocuk oyunları boş bir uğraş olarak değil, toplumun kurallarını hoşça vakit geçirerek anlama çabası olarak görülmekle birlikte kendini keşfetme süreci olarak değerlendirilmelidir.

Sonuç olarak günlük konuşma diline özgü pek çok kullanımı dışında, biyologlar ve psikologlar tarafindan kullanılan "oyun", "ciddi" veya "iş" olmayan neredeyse her etkinliği belirten kapsamlı bir terimdir. Bazı ölçütlere göre oyun daha belirgin olarak şöyle tanımlanabilir:

- Davranış kendiliğindendir ve birey için ödüllendiricidir.

- İçsel güdülenme gerektirir ve oyunun amacı oyundur.

- Oyuncu hasta ya da stresli değilse, davranış güvenli bir ortamda gerçekleşir.

- Yetişkinlerde oyunbaz olmayan davranışa göre ya tamamlanmamış ya da abartılıdır.

- Tekrar edilir. ( Bateson ve Martin, 2012).

Çocuklar için büyük önem taşıyan oyun; fiziksel, sosyal, bilişsel, dil gelişimi ve duygusal açılardan büyük önem taşımaktadır. Bu araştırmada çocuğun psiko-motor ve sosyal gelişimine katkısı üzerinde durulacaktır. Bilişsel ve dil gelişimi ile ilgili de yeri geldikçe bireyin sosyal gelişimi başlığı altında yer verilecektir. 
Oyun sırasında çocuğun bazı hareketleri sürekli olarak tekrar etmesi onun doğal olarak kas gelişimini hızlandırmaktadır. Ayrıca koşma, atlama, sıçrama, tırmanma, sürünme gibi fiziki güç gerektiren oyunlar da çocuğun solunum, dolaşım, sindirim ve boşaltım gibi sistemlerinin düzenli çalışmasını sağlamaktadır (Anılan, vd., 2003: 4).

Oyun oynayan çocuk gerçek hayattaki çeşitli sosyal rolleri yerine getirir. Oyun esnasında yaşadığı bir sorunu ifade edebilen çocuklar bu sorunun çözümüne yönelik adımlar atar. Oyun oynayan çocuk duygusal rahatlamanın yanı sıra enerji boşaltımı sayesinde daha da iyi hisseder. Oyun çocuğa kendini ifade etme firsatı verip özgüven ve benlik saygısının artmasına da yardımcı olmuş olur. Oyun kaygı ve endişelerin azalmasında rol oynarken aynı zamanda eğlenme, keyifli olma ve yaşam enerjisinin artmasında etkilidir (Selçuk, 2019: 25)

Çocuk oyunda üstlendiği ana-baba, kız-erkek gibi rollerle cinsel kimliğini kazanmaktadır. Yine ailesi içindeki rolleri üstlenerek ve yaşayarak görevleri, sorumlulukları, davranış biçimlerini öğrenmektedir. Çocuk oyun aracılığı ile kendine güven, kendini denetleme, iş birliği yapma, doğruluk ve disiplin gibi kişisel ve toplumsal alışkanlıkları kazanmaktadır. Çocuklar oyun oynarken diğer insanlarla iletişim kurmayı, gözlem yapmayı ve yardımlaşma duygularını geliştirebilmektedir. Ayrıca, başkalarına saygı gösterme, başkalarının hakkını ve kendi hakkını koruma, verilen görevleri üstlenme, herhangi bir konuda karar verip uygulayabilme ve iş birliği sağlayabilme gibi toplumsal kuralları da öğrenmektedir (Anılan, vd., 2003: 4).

Oyun ortamına girip sosyal ortama uyum sağlayacak olan çocuk, burada serbest davranacağı için davranışları burada deneyip büyüklerden aldıkları tepkilere göre o davranışların oturması, devam edilmesi sağlanacak ve örnek alınıp öyle hareket edilecektir. Aldığı tepkilere göre de yanlış davranışlarını düzeltme imkânı bulan çocuk bütün arkadaşlarıyla etkileşim halinde olacaktır.

Çocuk büyüdükçe grup aktivitelerine girebilmek için diğerleriyle oynama gereksinimi hisseder. Grup oyunları genellikle sözlü ya da fiziksel etkileşim yoluyla rol ve oyun araçlarını paylaşmayı içerir. Oyun tarafından sağlanan paylaşma, birlikte hareket edebilme, sıra bekleme ve oyunun kurallarını anlama gibi çok önemli becerilerle tanışmayı sağlar (Tekkaya, 2001'dan aktaran: Anılan, vd., 2003: 5). Bu açıdan da bakıldığında geleneksek çocuk oyunlarının pek çok sosyal içeriği bünyesinde barındırıp çocukları sosyalleştirdiği görülebilir.

$\mathrm{Bu}$ gerçeklerden hareketle farklı dinleri, kültürleri bünyesinde barındıran Mardin ilinde oynanmış çocuk oyunlarını inceleyip bu oyunların çocukların sosyal, fiziksel, bilişsel, dilsel, psiko-motor gelişimine katkısını incelemek hedeflenmiştir. $\mathrm{Bu}$ çalışmayla Mardin çocuk oyunlarının gelecek kuşaklara aktarılması, unutulmaması da sağlanmış olacağı ve daha sonraki çalışmalara kaynaklık edeceğine de inanılmaktadır.

\section{Yöntem}

Çalışma nitel araştırma yöntemlerinden doküman incelemesi ve yarı yapılandırılmış görüşme tekniği kullanılarak yürütülmüştür. Böylelikle halk kültürü ürünleri ile ilgili alan araştırmasından yararlanılmış ve elde edilen ürünler doküman incelemesine tabi tutulmuştur. Yapılandırılmamış görüşme yolu ile çok sayıda kaynak kişiden yararlanma yöntemiyle çocuk oyunlarına ulaşılmaya çalışılmıştır. Yapılandırılmamış görüşme, araştırmacıya konuyla ilgili olabilecek maddelerin sorulmasında büyük serbestlik sağlayan, soruların sıralamalarının sabit olmadığı, sorulan soruların görüşme esnasında gelişebildiği bir yöntem (Büyüköztürk, vd., 2019: 159) olarak tanımlanmaktadır.

\subsection{Verilerin Toplanması ve Analizi}

Çalışmada konu gereği ilkokul ve ortaokul başta olmak üzere eğitim ve öğretimin herhangi bir kademesinde yer almayanlarla da görüşmeler yapılıp notlar alınmıştır. Sınıfta, koridorda, okul bahçesinde, iş yerinde, kahvehanede, mahallede görüşmeler gerçekleştirilip derlemeler yapılmıştır. Derleme yapılırken çeşitli notlar alınmanın yanı sıra oyunun nasıl oynandığı ayrıntılı olarak tespit edilmiş, gözlemlerle hangi alanın gelişimine katkıda yaptığı tespit edilmiştir.

9 erkek 6 kadın ile yapılan görüşmeler neticesinde 20 tane oyun derlenmiş, 13'ü ''Herhangi Bir Nesneyle Oynanan Oyunlar' ve 7'si ''Herhangi Bir Nesne ile Oynanmayan Oyunlar' başlıkları altında incelenmiştir. Görüşme yapılan kaynak kişilerden 6'sı eğitim-öğretimin herhangi bir kademesinde yer almadığı gözlemlenmiştir.

Oynanıp isimlendirilmeyen oyunlara ya oyunla ilgili bir terim kullanılarak isimlendirilmiş ya da derlenen kişiden öneri alınıp isimlendirilmiştir. Derlenen oyunlar kaynak kişilerin verdiği şekliyle ele alınmış, görüşme bir sohbet havası içinde gerçekleştirilmiştir. Oyunlar düzenlenip bilgisayar ortamına aktarıldıktan sonra alan taraması ve uzman görüşü doğrultusunda bireyin gelişimine yararı incelenip gerekli tespitlerde bulunulmuştur.

\section{Bulgular}

\subsection{Mardin Geleneksel Çocuk Oyunları}

\subsubsection{Herhangi Bir Araçla Oynanan Oyunlar}

\subsubsection{Moris}

\section{Derleme Tarihi:2019}

Oyunun Mekânı: Geniş, düz bir alan

Oyunu Kimlerden Öğrendiği: Arkadaşlarından, büyüklerinden

\section{Oyun Aracı: Bilye}

Uygun büyüklükte çember çizildikten sonra kaç kişi, kaç bilye üzerine oynuyorsa o kadar bilye çemberin için uygun aralıklarla bırakılır. Daha sonra bilyelere nereden atış yapılacaksa çembere paralel bir çizgi çizilir. O çizilen çizgiye çemberin bitişiğinden bilyeler atılıp çizgiye en yakın kişiden başlamak üzere en uzak kalan kişiye doğru çemberdeki bilyeler çemberden çıkarılmak üzere atışlar yapılır. Bilyeler çemberden çıkarıldığında bilyeyi atan kişinin bilyesi çemberin içinde kalırsa oyundan çıkılır, kalanlar çemberdeki bilyeler bitene kadar oynamaya devam edilir. Bilyeler çemberden çıkarılıp bilyelerin sahibi olunur. (KK.1) 
$\mathrm{Bu}$ oyun incelendiğinde çocuğun gelişimine yararı şu şekilde incelenebilir:

- $\mathrm{Bu}$ oyun incelendiğinde önceden kuralların belirlenip o kurallara uyulması oyunun keyifle oynanıp bireylerin sosyalliğine katkıda bulunduğu söylenebilir.

- $\quad$ Atış sıralamasının belirlenmesi için yapılan atışın uygun hızda atılıp çizgiye en yakın olması gerektiğinden bireyin kendi gücünü kontrol ettiğini, bu gücünü öğrenip geliştirdiği şeklinde yorumlanabilir.

- Atışlar yapılırken bilyelere isabet ettirmek için alınan pozisyon ve dengede durup gücünü bilyesine aktarıp atışlar yapılması bireylerin psiko-motor gelişimini sağladığı gözlenmektedir.

\subsubsection{2. Çelik Çomak}

\section{Derleme Tarihi:2019}

Oyunun Mekânı: Düz geniş bir alan

Oyunu Kimlerden Öğrendiği: Arkadaşlarından ve büyüklerinden

Oyun Aracı: iki çubuk, çukur

Çelik çomak oyunu olarak da bilinen bu oyun hem tekli hem de takım şeklinde oynanılabilir. Yerde bir çukur oluşturulur ya da iki taş yan yana getirilip çelik boyunda ayarlanır. Çeliği en fazla sektiren kişi/grup tarafından oyun başlatılır. Oyuna başlayan kişi tarafindan çelik çukurun üstüne yatay olarak bırakıldıktan sonra çomakla çeliğe vurulup havaya kaldırılıp uzağa firlatılmaya çalışılır. Rakip takım tarafından ise çelik havada yakalanmaya çalışılır. Rakip takım tarafından çelik havada yakalanırsa oyunu başlatan takıma belirlenen puanı verilmez. Daha sonra çomak çukurun yanına bırakılır diğer takım tarafından çelik düştüğü yerden çukura ve çomağa değdirilmeye çalışılır. Rakip takım tarafından çelik çomağa değdirilirse puan rakip takım tarafından alınır. Değdirilmese diğer takım tarafından çelik alınıp sektirilmeye başlanır. Takım en fazla üç defa sektirebilir. 3 sektirmede bir puan alınır. Çelik uzağa atılır ve çukurla çeliğin düştüğü aradaki mesafe çomak boyuyla sayılır. Oyun başında belirlenen sayıya ulaşan takım tarafından oyun kazanılır. (KK.10)

$\mathrm{Bu}$ oyun incelendiğinde çocuğun gelişimine yararı şu şekilde incelenebilir:

- Ulaşılması gereken sayı önceden belirlendiği için kurallara uyma davranışı kazandırılabilir

- $\quad$ Oyuna başlayan kişi/grup olmak için çubuğu sektiren kişi psikolojik olarak kendinden çok büyük bir beklenti olduğundan dolayı normalin üstünde bir çaba gösterdiği gözlemlenmiş, bu durum ise takdir kazanmasını sağladığ 1 için öz güvenini geliştirdiği şeklinde yorumlanabilir.

- $\quad$ Çeliği uygun yüksekliğe kaldırıp vurma eylemi elgöz koordinasyonunu geliştirir nitelikte olduğu tespit edilmiştir.

- Çeliği yakalamaya çalışan kişinin de el-göz koordinasyonunu geliştirdiği yine gözlenmektedir.

\subsubsection{Tek Kale Futbol}

Oyunun Mekânı:5-6 metre uzunluğunda ve genişliğinde Oyunu Kimlerden Öğrendiği: Büyüklerinden

Oyun Aracı: Top, iki kale taşı

Oyuncu sayısının en az 5, en fazla 15-17 kişi olduğu bir oyundur. Geleneksel futbol için uygun alanın olmadığ durumlarda bu oyun oynanabildiği gibi bundan bağımsız olarak da oynanan bir oyundur. Sokak aralarında oynandığı için uygun oynama alanı olmadığı için tek kale şeklinde oynanmıştır. 3 korner bir penaltı sayılır. Kaleci ise ya mahallenin kalecisidir ya da en kötü oyuncu- genellikle seçilen en kötü oyuncudur- kalecidir. Maç 10 veya 15 'te biter. Takımları ise en iyi iki oyuncu birer oyuncu seçmeye başlayarak takımlar oluşturulmaya başlanır. Oyuncular seçildikten sonra dışarıda oyuncu kalırsa bu oyuncu verilen gol sayısı yarısına kadar bir tarafta, diğer yarıda ise diğer tarafta oynar. Kaleciden çıkan topa ulaşan ilk oyuncu direkt gol atamaz, ya arkadaşına pas verir ya da rakip bir oyuncuyu geçmelidir. Klasik futboldaki-on birer kişiyle oynan futbolgibi mevki yoktur. Herkes defanstır da forvettir de. Maç çekişmeli olmadığında kaptanlar oyuncu değiştirebilir. Mahalleler arası maç yapılırsa takımlar çoğunlukla aynı mahalledeki oyunculardan oluşur. (KK.2)

Bu oyun incelendiğinde çocuğun gelişimine yararı şu şekilde incelenebilir:

- Kuralların önceden belirlenip uyulması sosyal gelişimine katkı sağlandığı sonucunu vermektedir.

- Takım oluşturucuların otoritesinin kabulü gözlem yeteneğinin geliştiği ve deneyimlerin artarak kullanıldığı şeklinde bir sonucu vermektedir.

- Koşma, vurma, rakibi geçme, paslaşma vb. psikomotor davranışların bireyler tarafınca sıkça kullanıldığı görülmüştür.

- Ani olarak pas verme kararının verilmesi, rakipleri bir yere çekip topun arkadaşlara atılması gibi davranışların zihinsel etkinliklerin bireyler tarafinca etkili kullanıldığı sonucunu vermektedir.

- Geleneksel futbol oyunu benzeri olan bir oyunun değiştirilip oynanan yere uyarlanması yaratıcılığın etkili şekilde kullanıldığını göstermektedir.

- Sonda kalan tek kişinin de uygun kurallar çerçevesinde oyuna dahil edilmesi aitlik duygusuyla beraber empati yeteneğinin de oyuncular tarafinca kullanılıp geliştirildiği gözlenmektedir.

\subsubsection{4. $R \hat{e} z$}

Derleme Tarihi:2019

Oyunun Mekânı: Uygun her türlü alan

Oyunu Kimlerden Öğrendiği: Arkadaşlarından

Oyun Aracı: Tebeşir, üçer taş

Üçtaş oyununun diğer bir ismidir. Bir kare çizilir, çapraz olarak köşeden köşeye çizgi çizilir, yatay ve dikey çizgilerin de tam ortalarından karşı taraftaki çizginin ortasıyla 
birleştirilip karenin ortasında bütün çizgilerin geçtiği bir şekil çizilmiş olur. (KK.2)

İki kişiyle oynanan bu oyuna başlayacak kişinin belirlenmesiyle oynanmaya başlanır. Sayışmadan sonra oynayacak oyuncu belirlenir. Her oyuncunun aynı renkteki 3 taşını yatay, dikey veya çapraz olarak karenin üzerinde yerleştirilmesi amaçtır. Bundan dolayı rakibin taşlarını bu şekilde dizmesine izin verilmez. İlk oyuncu ilk taşını herhangi bir yere bıraktıktan sonra diğer oyuncu tarafından oyuna devam edilir. Taşlarını istenen şekilde dizebilen ilk oyuncu tarafindan oyun kazanılmış olup oyun biter. (KK.2)

$\mathrm{Bu}$ oyun incelendiğinde çocuğun gelişimine yararı şu şekilde incelenebilir:

- Oyuna başlayacak kişinin belirlenmesinin, her birinin bir hamle yapabilmesi gibi durumların bireylerde kurallara uyma bilincini geliştirmektedir.

- İki-üç hamle sonrasını düşündüren bir oyun olması hasebiyle bireylerin strateji geliştirme yeteneğini geliştirdiği şeklinde bir sonuç vermektedir.

- Sonuçta yenen ve yenilenin belirlenmesi ile bireylere öz güven ve ders çıkarma duygusunu kazandırmaktadır.

\subsubsection{Renk Tutmaca}

Derleme Tarihi:2019

Oyunun Mekânı: Kapalı alan

Oyunu Kimlerden Öğrendiği: Arkadaşlarından,
büyüklerinden

Oyun Aracı: Renkli karelerin olduğu herhangi bir materyal

Evde oynanan bir oyundur. Renk seçecek kişi öncelikle belirlenir. Daha sonra diğer oyuncular da renk seçicinin arkasına gidip söylenen renkleri basarak ilerler. Yanlış yapan oyun dişı kalırken hiç hata yapmayan ise başa geçip renk seçici olur. Oyun bu şekilde oynamaya devam edilir. (KK.13)

$\mathrm{Bu}$ oyun incelendiğinde çocuğun gelişimine yararı şu şekilde incelenebilir:

- Renkleri söyleyeceğin belirlenmesi, yanlış yapanın oyundan çıkacağının söylenmesi bireylerin grupça karar alma ve buna uyma yeteneğini geliştirmektedir.

- Renklerin söylenip anlaşılması gerekmesi ifade edici ve alıcı dil yeteneğini, söylenen renklere basılması ve bunun hemen yapılması gerekmesi ise bireylerin zihinsel gelişimini olumlu yönden geliştirdiği sonucuna varılmaktadır.

- Yeni renk seçicinin belirlenmesi bireylerin öz güven duygusunu geliştirmektedir.

- $\mathrm{Bu}$ oyunda hizli olan oyuncunun rakiplerini şaşırtmaya çalışıp ayağını hızlıca yanlış renge götürüp sonrasında hemen doğru renge basması bireylerin strateji geliştirme yeteneğini geliştiren bir husustur.

\subsubsection{Nişan Oyunu}

Derleme Tarihi:2019
Oyunun Mekânı: Geniş bir alan

\section{Oyunu Kimlerden Öğrendiği: Arkadaşlarından}

Oyun Aracı: Sapan, şişe/teneke/soba borusu

En az iki kişiyle oynanır. Yine en az üç hedefin olduğu, çevredeki koşullara göre şişe, teneke, soba borusu veya taşın dikey olarak dikildiği ve sapanla atışların yapıldığı bir oyundur. Atışlar en az 15 metre uzaktan yapılır. En çok hedef deviren kişice oyun kazanılır, en az düşüren veya düşüremeyen kişice ceza alınır. Bu cezalar ise oyunun nerede oynandığına göre değişiklik gösterir. Kırlarda oynandığında yenilene koyun ve keçiler baktırılırken köyde ise ona ya dükkândan bir şey aldırılır ya da meyve getirtilir. (KK.3)

Bu oyun incelendiğinde çocuğun gelişimine yararı şu şekilde incelenebilir:

- Atışların on beş metreden yapılması bireylerin kurallara uyma davranışını geliştirir mahiyettedir.

- Yenilenin cezasını çekmesi kazananların ödüllerini alması oyuncuların ödül ceza kavramını öğrenmesini sağlar niteliktedir.

- Oyun için gerekli araçların veya oyun sonucunda verilecek ödüllerin kesin olarak belirlenmeyip çevre koşullarına göre uyarlanması bireylerin yaratıcılığını geliştirmektedir.

- Oyun sonunda cezasinı yerine getirmeyenin oyunlara alınmamasinın ve onunla konuşulmamasını kurallara uyma davranışını göstermektedir.

- Sapanla nişan alınıp hedefin düşürülmesi bireylerde el-göz koordinasyonunu geliştirdiği şeklinde yorumlanmaktadir.

- Hedefe atışlar yapılırken en uygun taşın belirlenip seçilmesi bireylerde deneyimlerin elde edilmesi ve bu deneyimlerin uygun şekilde kullanılması hususu elde edilmektedir.

\subsubsection{Tekerlek Döndürmece}

Derleme Tarihi:2019

Oyunun Mekânı: Düz uzun bir yol

Oyunu Kimlerden Öğrendiği: Arkadaşlarından, büyüklerinden

\section{Oyun Aracı: Araba tekerleği lastiği}

Kaç kişi varsa genellikle yokuş aşağı bir yola gidip tekerlekleri hep beraber aşağıya doğru hızlıca döndürülür ve önceden belirlenen çizgiye kadar tekerlek hızlandırılabilir. Belirlenen çizgiden sonra tekerleğe dokunan olursa oyundan çıkmış sayılır. Oyunun sonunda tekerleğini en uzağa doğru döndürebilen kişice oyun kazanılır. (KK.15)

$\mathrm{Bu}$ oyun incelendiğinde çocuğun gelişimine yararı şu şekilde incelenebilir:

- Tekerleğin nereye kadar döndürüleceği, ne zaman döndürülmeye bașlanacağı gibi durumların önceden belirlenmesi bireylerin kuralları tanıma ve kurallara uyma bilincini geliştirmektedir. 
- Tekerleklerin döndürülmesi, tekerlekle birlikte koşulması ve tekerleği yere düşürmeme gayreti, çizgiye yakınlığın kontrol edilmesi bireylerin psiko-motor gelişimine katkı sunmaktadır.

- Çocukların beraberce oynaması ise bireylerde ait olma duygusunu geliştirdiği gözlemlenmektedir.

- Tekerleklere nereye kadar müdahale edebileceklerini belirlemelerini bireyin grup kararını alma yeteneklerini ön plana çıkarmaktadır.

- Oyunu kazanan kişinin ise sevinç ve mutluluğu yine öz güvene katkı sunmaktadır.

\subsubsection{Citta}

\section{Derleme Tarihi:2019}

Oyunun Mekânı: Çamurlu bir alan

\section{Oyunu Kimlerden Öğrendiği: Arkadaşlarından}

Oyun Aracı: Düz sivri çubuk ve saplanabilecek çamurlu bir yer

Oyun en az iki kişiyle en fazla 4-6 kişiyle oynanır. Oyuncu sayısı yeterliyse grup hâlinde de oynanabilir. İlk atacak kişi belirlendikten sonra gruplar oyuna başlanılır. Unutulmamalıdır ki ilk atan kişi dezavantajlıdır. Çubukların kalınlığının birbirine eşit veya yakın olması gerekmektedir. Çubukların yerle ucu arasında bir karış kalırsa veya biri onu yere değdirmeyi başarıp çubuğu çamura saplayabilirse onun tarafından çubuk kazanılmış olur. İki grup kendisine hedef bir çubuk seçilip o kazanılmaya çalışılır. Daha sonra çubukları kazanan grup tarafindan paylaşılır. (KK.15)

$\mathrm{Bu}$ oyun incelendiğinde çocuğun gelişimine yararı şu şekilde incelenebilir:

- Önceden belirlenen kurallara uyulması, bireylerin kuralları tanıma ve kurallara uyma davranışını geliştirmektedir.

- Çubukların çamura sağlam saplanmasını sağlayacak şekilde çubukların atılması bireylerin psiko-motor becerileri geliştirmektedir.

- Kendi aralarında bir hedef seçip ona odaklanmaları bireylerin zihinsel gelişimine katkı sunmaktadır.

- Kazanılan çubukların grup içinde paylaşılması ise bireylerde paylaşma duygusunu geliştirir niteliktedir.

\subsubsection{Terlik Atmaca}

\section{Derleme Tarihi:2019}

Oyunun Mekânı: Genişçe bahçelerde oynanır

Oyunu Kimlerden Öğrendiği: Arkadaşlarından

Oyun Aracı: Teneke, terlik

Belirlenen tenekenin içine terlikler isabet ettirilmeye çalışılır. Onun için bir teneke belirlenen yere bırakılıp yine önceden belirlenen uzaklıktan terlikler tenekenin içine atılmaya çalışılır. Herkesin seçtiği terlik tenekeye atılıp içine konulmaya çalışılır. Terliğini tenekenin içine atamayan kişice diğer oyuncular kovalanmaya çalışılır. Hepsi yakalandıktan sonra bu sefer diğer oyuncularca tenekenin içine terlikler atılmaya çalışılır. Oyun bu şekilde oynanmaya devam edilir. (KK.14)

Bu oyun incelendiğinde çocuğun gelişimine yararı şu şekilde incelenebilir:

- Önceden belirlenen kurallara uyulması, bireylerin kuralları tanıma ve kurallara uyma davranışını pekiştirmektedir.

- Çocukların arkadaşlarıyla beraber oynaması onların gruba ait olma duygusunu geliştirmektedir.

- Bir hedefin seçilip ona odaklanılması bireylerin zihinsel gelişimini geliştirmektedir.

- Ebeden kaçıp yakalanılmamaya çalışma bireylerin psiko-motor gelişimine atkı sunmaktadır.

\subsubsection{0. Çizk}

\section{Derleme Tarihi:2009}

Oyunun Mekânı: Genişçe boş bir alan

Oyunu Kimlerden Öğrendiği: Arkadaşlarından, büyüklerinden

Oyun Aracı: Taş, yuvarlak bir taş

Oyuncular tarafından kendilerine uygun bir taş seçilir. Büyük bir taşın üstüne de yuvarlak bir taş bırakılır. Daha sonra ebe seçilir. Ebe ise o büyük taşın yanında bekler. Diğer oyuncular ise taşlarını yuvarlak taşa atmak üzere belirlenen bölgeye gider. Oyuncular tarafından atılan taşlarla yuvarlak taş büyük taşın üstünden düşürülmeye çalışılır. Taş düşürüldükten sonra taşını atanlar gidip taşını almaya çalışır. Taşı bekleyen de onlara elini değdirip oyuncular ebelenmeye çalış1lır. Ebelenen kişice bu sefer taş beklenmeye başlanır. Oyun bu şekilde oynanmaya devam edilir. (KK.7)

Bu oyun incelendiğinde çocuğun gelişimine yararı şu şekilde incelenebilir:

- Önceden belirlenen kurallara uyulması, bireylerin kuralları tanıma ve kurallara uyma davranışını pekiştirmektedir.

- Uygun taşın alınıp kullanılması bireylerin geçmiş deneyimlerinden yola çıkarak hareket ettiğinden onların zihinsel gelişimine olumlu katkıda bulunmaktadır.

- Yuvarlak taşı düşürmeye çalışırken taş atma, koşup taşı almaya çalışma, ebenin yuvarlak taşı hızlıca eski yerine bırakmaya çalışması gibi davranışlar ise bireylerin psiko-motor becerilerinin gelişimine katk1 sunar.

- Yuvarlak taşı atan kişinin öz güven duygusunu geliştiren bir davranış olduğu sonucuna varılmaktadır. 


\subsubsection{Yă̆lı Kaylş}

\section{Derleme Tarihi:2019}

Oyunun Mekânı: Açık, geniş bir alan

Oyunu Kimlerden Öğrendiği: Arkadaş ve büyüklerinden

\section{Oyun Aracı: Kemer}

Kemeri saklayacak kişi belirlenir. Kemerin nerelere vurulamayacağı belirlenir. Kemeri saklayacak kişi belirlendikten sonra belirlenen bölgede gözlerini kapatarak ve sırtını kemerin saklanacağı alana dönerek kemerin saklanması beklenir. Kemer saklandıktan sonra kemeri saklayan kişi kemeri arama işareti vererek kemerin aranmasına izin verilmiş olur. Ebece, kemeri arayanlara kemere yakınlık veya uzaklıklarına göre sıcak-soğuk denilir. Kemere yakınlığa göre bu durum abartılarak ifade edilir. (buzhane, sımsıcak vs.) Kemer, ilk bulan kişice alınıp oyunculara savrulup onlara vurulmaya başlanır. Tabii kemer ebeye vurulamaz. En son kişi, belirlenen alan sınırları içine girene kadar kemer bulunan kişice oyunculara vurulmaya çalışılır. Herkes o alana gittikten sonra bu sefer kemer bulunun kişice saklanır. Oyun bu şekilde oynanmaya devam edilir. (KK.6)

Bu oyun incelendiğinde çocuğun gelişimine yararı şu şekilde incelenebilir:

- Önceden belirlenen kurallara uyulması, bireylerin kuralları tanıma ve kurallara uyma davranışını geliştirip pekiştirir.

- Hep beraber oynandığı için bireylerde ait olma duygusunu geliştirir niteliktedir.

- Ebe kemeri arayanların yakınlıklarına göre "'sıcaksoğuk" kelimelerini abartarak ifade etmesi bu işi yapanların dilsel gelişimini olumlu yönde etkilemektedir.

- Kemerin nerelere saklanmış olabileceğinin düşünülüp ona göre hareket edilmesi, kemeri görenin kemeri görmezden gelip kemeri arayanların kemere yaklaşmasını beklemesi gibi davranışlar bireylerin zihinsel gelişimine katkı sunan davranışlar olarak kabul edilmektedir.

- Kemeri savurup yasaklı olmayan bölgelere denk getirmeye çalışılması, kaçma gibi davranışların olması ise bireylerin psiko-motor gelişimini destekleyen davranışlardır.

\subsubsection{Birbirine Binmece}

Derleme Tarihi:2019

Oyunun Mekânı: Açık, geniş bir alan

Oyunu Kimlerden Öğrendiği: Arkadaşlarından

Oyun Aracı: Taş

En az iki oyuncu ile oynanan bu oyun bir nişan alıp isabet ettirme oyunudur. Bundan dolayı herkes tarafından oyun için en güzel taşın seçilmesi lazım. Oyuncuların taşlarını nereden atılacağı belirlendikten sonra taşlar atılmaya başlanır. Amaç, taşın başka bir oyuncunun taşına değdirilip kendi taşının o taştan olabildiğince uzağa gitmesinin sağlanmasıdır. Bunun için de o taşın seçimi bu oyunda çok önemlidir. Taşını diğer oyuncuların taşına değdiren kişi, iki taş arası taşı vurulana biner. Oyun bu şekilde oynanır. (KK.6)

Bu oyun incelendiğinde çocuğun gelişimine yararı şu şekilde incelenebilir:

- Önceden belirlenen kurallara uyulması, bireylerin kuralları tanıma ve kurallara uyma davranışını destekler.

- Oyuncuların kendileri için en güzel taşı belirleyip ona göre taşlarını seçmesi deneyimlerin kullanıldığını ve dolayısıyla bunu kullananların zihinsel gelişimi olumlu yönde gelişeceği sonucuna varılabilir.

- Taşın rakip taşına değdirilip en uzağa gitmesi için uygun şekilde atılması, birbirine binerken düşmemek için dengede kalma, sırtında taşırken sırtındakini dengede tutma gibi davranışlar da bireylerin psiko-motor gelişimine katk1 sunmaktadir.

- Taşı vuranın ve taşı vurulanın belirlenen kurallara göre ödül alması veya cezasını çekmesi çocukların ödül ve ceza kavramlarını öğrenmesini sağlamaktadır.

\subsubsection{Can}

\section{Derleme Tarihi:2019}

Oyunun Mekânı: Genişçe bir alan

Oyunu Kimlerden Öğrendiği: Arkadaşlarından

Oyun Araci: Top

İki takım halinde oynanan bir oyundur. İki kişi tarafından takımlar oluşturulur. Yakan Top adıyla da bilinen bu oyunda ortada iki takımında oyuncuları bulunur. Nereden atış yapılacağı belirlenip oyuncular tarafından belirlenen yerlere gidilir. Oyuncuyu elemek için atılan top yere değmeden havada topu yakalanırsa iki hakkı olmuş olur. İki takım karşılıklı olarak yerlerini aldıktan sonra alan tam ortadan ikiye ayrılır. A takımı oyuncusu kendi takımı tarafinda, B takımı oyuncusu da kendi takımı tarafında durulup karşı tarafin oyunculardan gelen topun kendisine çarpmaması sağlanır veya o topun yere değmemesi şartıyla yakalanmaya çalış1lır. Top kendisine çarpıp havada yakalanmazsa bir can daha kazanmışsa oynamaya devam edilir ya da can hakkı yoksa oyundan çıkılıp yerine sıradaki oyuncu arkadaşı gelip oynanmaya devam edilir. Takımdaki oyuncular bitene kadar buna bu şekilde oynanmaya devam edilir. Oyuncuları elenen takım elenmiş olur. (KK.9)

Bu oyun incelendiğinde çocuğun gelişimine yararı şu şekilde incelenebilir:

- Önceden belirlenen kurallara uyulmas1, bireylerin kuralları tanıma ve kurallara uyma davranışını destekler. 
- $\quad$ Arkadaşlarıyla oynadıkları için bireylerde ait olma duygusunu geliştirdiği sonucu elde edilmektedir.

- Topu hizlica yakalama, topu ortadakine değdirmeye çalışırken firlatma tarzı, topun değmesini önlerken havaya zıplama veya kenara kaçma gibi davranışlar bireylerin psiko-motor gelişimini üst seviyeye taşımaktadır.

- Ortadaki oyuncunun kendisine atılan topun yakalayıp yakalayamamasını karar vermesi; havaya mı zıplaması gerektiğine, yoksa kenara mı kaçması gerektiğine karar vermesi bu kişinin zihinsel gelişimini etkiler mahiyettedir.

- Oyuncu topu yakaladığında rakip takımı kızdırmak amacıyla onlara teşekkür etmesi bireylerin psikolojik gelişimine olumlu yönde etki ettiği sonucuna varılmaktadır.

\subsubsection{Herhangi Bir Araçla Oynanmayan Oyunlar}

\subsubsection{Ebe}

\section{Derleme Tarihi:2019}

Oyunun Mekânı: Açık veya geniş bir alan

\section{Oyunu Kimlerden Öğrendiği: Arkadaşlarından}

Öncelikle ebe seçilir. Yanındakilerin kaçması için belirlenen sayıya kadar sayıp kendisinden kaçanlara el değdirilmeye çalışılır. Ebenin eli bir oyuncuya değdirildikten sonra o oyuncu ebe olmuş olur. Bu sefer yeni ebe, belirlenmiş sayıya kadar saydıktan sonra oyuncular kovalanıp ebelenmeye çalışılır. Oyun böyle oynanmaya devam edilir. (KK.4)

Bu oyun incelendiğinde çocuğun gelişimine yararı şu şekilde incelenebilir:

- Önceden belirlenen kurallara uyulup ona göre hareket edildiği için bireylerde kurallara uyma davranışının geliştirdiği gözlemlenmektedir.

- Ebeden kaçıp aradaki mesafe korunmaya çalışılması için koşulması ihtiyacı bireylerin psikomotor gelişimini olumlu etkilediği görülmektedir.

- Kaçan kişinin ani olarak kaçma yönünü değiştirmesi o kişinin ani karar verme yeteneğini geliştirdiği sonucu elde edilmektedir.

- Çocukların hep birlikte oynaması çocuklarda gruba aitlik duygusunu geliştirdiği gözlemlenmiştir.

- Ebenin hiçbir oyuncuyu yakalayamaması sonucu birinin kendini ele verip ebeye yardım etmeye çalışması oyuncularda bağlılık ve yardım duygusunu geliştirdiği sonucuna varılmaktadır.

\subsubsection{Amerika}

Derleme Tarihi:2019

Kaynak Kişi: Hatip Gayır

Oyunun Mekânı: Açık veya geniş bir alan

Oyunu Kimlerden Öğrendiği: Arkadaşlarından
Bu oyun en az 4-5 kişiyle oynanır. Öncelikle ebe seçilir. Ebe seçildikten sonra oynayan çocukları kovalayacak çocuk tarafindan belli bir sayıya kadar sayılır ve oyuna başlanmış olunur. Ebenin amacı bütün çocukları yakalamaktır. Yakalanan oyuncular da ebeye yardım edip bir an önce bütün oyuncular yakalanmasını sağlarlar. Bütün oyuncular yakalandıktan sonra ebesini yapan oyuncu hariç diğerleri ebeyi belirledikleri yöntemle ebe yeniden seçilip oyuna böylece devam edilir. (KK.4)

Bu oyun incelendiğinde çocuğun gelişimine yararı şu şekilde incelenebilir:

- Ebenin seçilmesinin bireylerde sosyal gelişimi olumlu yönde etkilemektedir.

- Önceden belirlenen kurallara uyulup hareket edilmesi bireylerin kurallara uyma davranışını pekiştirir.

- Kovalayıp-kovalananın koşup ani yön değiştirmeleri o kişilerin psiko-motor davranışları geliştirmektedir.

- Yakalanan kişinin oyundaki rolünü hemen değiştirip yakalamaya çalışan kişiye dönüşmesi o kişilerde rol ve koşulları kabul etme yeteneğini geliştirir.

- Birini kovalayıp yakalayana kadar onun peşini bırakmaması bireylerde hedefe odaklanma duygusunu pekiştirmektedir.

\subsubsection{3. Ölüm Oyunu/Simit Oyunu}

\section{Derleme Tarihi:2019}

Oyunun Mekânı: Açık, geniş bir alan

\section{Oyunu Kimlerden Öğrendiği: Arkadaşlarından}

$\mathrm{Bu}$ oyunda en az 4-5 kişiyle oynanır. Öncelikle ebe belirlenir. Ebe belirlendikten sonra önceden çizilmiş olan çemberin içine nefesini uzatarak "Simiiit'" diye bağırıp oyunculardan biri yakalamak üzere girilir. İçine girip arkadaşlarının uygun pozisyonlarını almalarını bekledikten sonra onları yakalamaya çalışır. "Simiiiit'" diye bağırırken nefesi biter ve çemberin içine arkadaşlarına yakalanmadan giremezse bütün oyunculardan dayak yer ancak nefesi yetip $\mathrm{o}$, herhangi bir oyuncuyu yakalarsa bu sefer yakalanan kişi dövülür. Yakalanan kişi dayağını yedikten sonra ebesini yapmak üzere çembere girilir. Bu sefer yeni ebe tarafindan biri yakalanmaya çalışılır. Oyuna bu şekilde devam edilir. (KK.6)

Bu oyun incelendiğinde çocuğun gelişimine yararı şu şekilde incelenebilir:

- Ebenin seçilmesinin bireylerin sosyal gelişimine katk1 sunmaktadır.

- Önceden belirlenen kurallara uyulup buna göre hareket edilmesi bireylerin kurallara uyma davranışını pekiştirmektedir.

- İlgili sözcügüun söylenip nefesi sözcüğü söylemeye yetinceye kadar çembere dönülmemesi kişilerde 
nefes yönetimi gelişimini olumlu yönde etkilemektedir.

- Ödül veya cezaya uyulması bireylerin sosyal kuralları tanımasını sağlamaktadır.

\subsubsection{Sabuha}

\section{Derleme Tarihi:2019}

Oyunun Mekânı: Geniş bir alan

Oyunu Kimlerden Öğrendiği: Arkadaşlarından,
büyüklerinden

Geceleri oynanan bir oyundur. En az altı kişiyle oynanan bir takım oyunudur. İki takım kurulduktan sonra ilk saklanacak takım belirlenir. Daha sonra o takım saklanır. Saklanacak takım tam olarak saklandıktan sonra onları arasınlar diye "sabuha" diye bağırılır ve aranmaya başlanırlar. O takımdakiler bulunduktan sonra bu sefer arayan takım saklanır. Oyun bu şekilde oynanmaya devam edilir. (KK.5)

Bu oyun incelendiğinde çocuğun gelişimine yararı şu şekilde incelenebilir:

- İlk saklanacak grubun ve kuralların belirlenmesinden grupça karar verilmesi bireylerin grupça davranış oluşturma yeteneğini geliştirmektedir.

- Geceleyin nerede görülemeyeceğinin tahmin edilip ona göre saklanılması bireylerin zihinsel gelişimini olumlu yönde geliştirmektedir.

- Grup içinde hareket edilmesi bireylerin bir gruba ait olma yeteneğini geliştirmektedir.

\subsubsection{Körebe}

Derleme Tarihi:2019

\section{Kaynak Kişi: Beyaz Derin}

\section{Oyunun Mekânı: Kapalı Alan}

Oyunu Kimlerden Öğrendiği: Arkadaşlarından,
büyüklerinden

En az üç kişiyle oynanır. Karanlık bir ortamda oynanması gerektiğinden bir odaya gidilip odanın ışıkları kapatılır veya gündüzse odanın çok karanlık olması lazım. Ebe seçildikten sonra, ebe diğer oyuncuları yakalamaya çalışıp isimleri tahmin edilmeye çalışılır. İsim yanlışsa yakalanan kişi ismini söyler ve ebe tarafindan tekrar başka biri yakalanmaya çalışılır. Ebe tarafından biri yakalanıp isimleri doğru çıkarılırsa bu sefer diğer oyuncu ebe olmuş olur. Oyun böyle oynanmaya devam edilir. (KK.12)

Bu oyun incelendiğinde çocuğun gelişimine yararı şu şekilde incelenebilir:

- Ebenin seçiminin grup kararı ile yapılması bireylerin sosyal gelişimine olumlu anlamda katkı sunmaktadir.

- Belirlenen kurallara uyulup ona göre hareket edilmesi yine bireylerin sosyal gelişimine katk1 sunar niteliktedir.
- Yakalanan kişinin çeşitli fiziksel özelliklerinin tahmin edilip söylenmesi gerektiği için bireylerde zihinsel gelişim üst seviyeye çıkmaktadır.

- Koşma, yakalama gibi davranışlardan dolayı bireylerin psiko-motor gelişimleri üst seviyeye taşınmaktadır.

\subsubsection{Sobe}

Derleme Tarihi:2019

Oyunun Mekânı: Okul sokak, ev

Oyunu Kimlerden Öğrendiği: Arkadaşlardan, büyüklerinden

Saklambaç olarak bilinen oyunda en az iki kişiyle de oynanabilen bir oyun olmasına rağmen iki kişiyle oynandığ görülmediği söylenebilir. Sayışmayla ebe seçildikten sonra önceden belirlenen sayıya kadar sayılır. Bu oyunda belli bir alan belirlenip o bölgeye ellerini değdirip sobe denilir. Belirlenen yerde gözler kapatılıp sayılmaya başlanır. Yine bu belirlenen bölge sobelenir. Gözler açılmadan önce 'Sağım, solum, önüm, arkam, hepsi sobe!'’ denilip gözler açılır. Gözler bunu söylenmeden açılırsa oralarda biri varsa orası sobeleneceğinden tekrar sayılmak zorunda kalınır. Saklanılacak alan önceden belirlendiği için bu alanın dışına çıkan kişiler bulunmuş sayılır. Bulunan kişiler ise farklı kelimeler belirlenerek ebenin kendilerine doğru gelindiğini veya uzaklaşıldığı haber verilebilir. Saklananları arayan kişi isimleri karıştırırsa üç-dört defa 'Çanak çömlek patladı!.." denilip kişi yine saklanır. Sadece bir kişi sobelerse-önceden belirlenen kurala bağlı olarak değişebilir- bulunan herkes kurtarılır. Oyun, saklanan son kişi bulunana kadar böyle devam eder. (KK.8)

Bu oyun incelendiğinde çocuğun gelişimine yararı şu şekilde incelenebilir:

- Ebenin grupça belirlenmesi bireylerin sosyal gelişimine akaktı sunar.

- Belirlenen sayıya kadar sayılması, gözün açılmaması, belirlenen alanın dişına çıkılmaması gibi davranışların bireylerin kural bilincini ve kurallara uyma davranışlarını pekiştirmektedir.

- Bulunan veya sobelemek isteyen kişi koştuğu için bu durum onların psiko-motor gelişimini desteklemektedir.

- Bulunan kişiler ise ebeyi yanıltmak amacıyla belirledikleri kelimeleri söylemeleri kişilerin dilsel ver zihinsel gelişimine katkı sunmaktadır.

- Ebenin oyuncuların çıkmasını sağlamak için sobe bölgesine yakın bir yerde saklanıp saklananların çıkmasını beklemesi bireylerde zihinsel gelişime katk1 sunar.

\subsubsection{Perdele}

Derleme Tarihi:2019

Oyunun Mekânı: Okul içi, okul bahçesi, sokak

Oyunu Kimlerden Öğrendiği: Arkadaşlarından 
Üç kişiyle oynanan bir oyundur. Oyunu başlatan kişi perdele deyip çizilen ilk kutucuğa atlanıp oynama sıraları söylenir. Kutucuğa atlanıp "bir, iki, üç" deyip sıralar belirlenir. Oyunda istenen sayıda kareler çizilir. İlk oynayan kişi tarafindan ise bu karelerin çizgilerine basılmadan iki elini tutan arkadaşları beraberinde sonraki karelere gitmeye çalışılır. Her sonraki kareye basıldığında ilerleyen kişi "perdele" der. Onun elinden tutan arkadaşları ise "hayır" veya "evet" der. Hayır denilirse oyuna devam edilir, ever denilirse oynama sırası diğer arkadaşlarına geçmiş olur. Çizgiye basan kişi elenir, sıradaki oyuncu tarafından oynanmaya başlanır. Oyuna bu şekilde devam edilir. (KK.11)

Bu oyun incelendiğinde çocuğun gelişimine yararı şu şekilde incelenebilir:

- Önceden belirlenen kurallara göre ilk oynayacak oyuncunun belirlenmesi bireylerin sosyal gelişimini geliştirmektedir.

- Karenin çizgilerine basan kişinin yerine sıradaki oyuncunun geçmesi kişilerde kurallara uyma bilincini geliştirmektedir.

- Adımların ne kadar büyüklükte atılacağı hesaplanıp ona göre adımların atılması bireylerde zihinsel gelişimin sağlamasına katkı sunmaktadır.

- Oynama sırası belirleme ve adımların atılması gibi hareketler bireylerin psiko-motor gelişimine katkı sunmaktadır.

- Oynayan kişinin elinden tutulması ve oyun içinde beraber olma gerekliliği kişilerde ait olma duygusunu geliştirmektedir.

\section{Sonuç, Tartışma ve Öneriler}

\subsection{Sonuç}

Görüşme ve kaynak kişilerle görüşülerek elde edilen Mardin çocuk oyunlarını herhangi bir araçla oynanan çocuk oyunları ve herhangi bir araçla oynanmayan çocuk oyunları diye sınıflandırma yapılmıştır. Oyun farkı gözetmeden çalışmada, genel anlamda çocuk oyunlarının kültürle, halk bilimiyle, çocuğun gelişimiyle ilgili olduğu ve oyunların bireylerin gelişimine katkı sunduğu sonucu elde edilmiştir.

Oyunlarla ilgili ulaşılan başka bir sonuç ise şudur: Kaynak kişilerle yapılan görüşmelerde oyunların ya okulda ya da genişçe yerlerde oynandığı görülmüştür. Her yerde inşaatların artmasıyla oyun alanlarının da azalması, teknolojinin gelişmesiyle bilgisayar oyunlarının artması, apartman kültürünün gelişmesiyle oyun alanlarının daralması, komşuya güvenin azalması, sınav sayısının ve rekabetin artmasıyla çocuğun çocukluğunu yaşamaması gibi sebeplerin de çocuk oyunlarına etkisinin olduğu görülmektedir.

"Renk Tutmaca" oyununda söylenen kişinin söylediklerine uyulması, "Sobe" oyununda belirlenen alanların dışına çıkmadan saklanılması, "Amerika" oyununda yakalananların ebeye yardım edip diğerlerini yakalaması, "Nişan" oyununda kişinin verilen cezalara uyup gereğini yapması sosyal gelişimle birlikte dilsel, kültürel gibi pek çok alanda olumlu gelişmeye etki ettiği sonucu elde edilmiştir.

Ebeden kaçıp yakalanmamaya çalışılan oyunlarda psikomotor gelişim alanını olumlu etkiler. 'Rêz" oyununda ise zihinsel gelişimi olumlu etkileyen bir oyun olduğu için diğer oyunlar gibi bu oyun da stratejinin önemli olduğu görülmektedir. Anlatmaya çalıştığımız gibi geleneksel çocuk oyunlarını oynayanların psiko-motor, kültürel, sosyal, dilsel, fiziksel, zihinsel gelişim alanlarını olumlu etkilediği görülmektedir. Bu da ailelerin, okulların oyunları oynamayı destekleyici aktivitelerde bulunması gerektiği yönünde çaba sarf etmeleri gerektiği şeklinde bir sonuç vermektedir.

Çizk oyununda atış yaparken, Simit kovarken nefesini kontrol ederken, sobe oyununda saklananları ararken sobe bölgesinden uzaklaşırken saklananlardan birinin sobelemek için koştuğunda vb. oyunlarda psiko-motor faaliyetler içinde bulunmakla birlikte kendi vücudunu ve gücünü tanıyıp geliştirdiği gözlemlenmiştir.

\subsection{Tartışma}

Çocuk oyunlarının kültürle, halk bilimiyle, çocuğun gelişimiyle ilgili olduğu ve oyunların bireylerin gelişimine katk1 sunduğu gerçeğinden hareketle yapılan alan taraması doğrultusunda konu tartışılmaya çalışılmıştır.

Artvin'de Çocuk Oyunları adlı çalışma (Erdem, 2019) ile yapılan bu çalışma arasında genel benzerlik olduğu görülmüştür. Yine oyunların çocukların gelişimine katkı sunduğu yönünde yapılan başka bir çalışmada; öğretici ve geliştirici bilgisayar oyunlarının uygun zaman ölçülerinde ve kontrollü oynanması durumunda çocuk ve gencin gelişimine katkı sağladığı ifade edilirken (Yalçın, vd., 2016: 134) bunun geleneksel çocuk oyunları için de geçerli olduğu gerçeğine vurguda bulunulmuştur.

Her yerde inşaatların artmasıyla oyun alanlarının da azalması, teknolojinin gelişmesiyle bilgisayar oyunlarının artması, apartman kültürünün gelişmesiyle oyun alanlarının daralması, komşuya güvenin azalması, sınav sayısının ve rekabetin artmasıyla çocuğun çocukluğunu yaşamaması gibi sebeplerin de çocuk oyunlarına etkisinin olduğu gerçeği yapılan benzer çalışmalarda da (Erdem, 2019: 182-183; Sülün, 2019: 152-153) görülmüştür. Dış mekânlarda çocuğun becerilerinin geliştiğine, öğrenme yeteneğinin arttığına, kişiliğinin oturduğuna katkı sağladığını ifade eden Selçuk (2019: 162) oyun alanlarının genişletilmesinin önemine dikkati çekmiştir. Çakırer Özservet, (2015) çalışmasında oyun mekânının esnek kullanıma, yaratıcı fikirlere izin vermesi gerektiği aksi durumda aşırı kontrol oyunun doğasını mahveder. Dış mekânda oynama, kendi yeteneklerini test etme anlamında çocuk için oldukça önemlidir. Günlük hayata dâhil olma firsatı çocuğun yetişkinlerin dünyasına adapte olması için dış mekânda çocuğa sunulmalıdır. Çocuklar aktivite olarak en çok planlanmamış enformel oyunları sevmektedirler. Malesef çocuk parkları bugün çocuklar için planlanmış tek resmi dış mekânlar konumundadır.

Araştırmamızda derlenen oyunlar için de oynama alanlarının daraldığını, çocukların belli başlı oyunları eskisi gibi oynayamadığı görülmüştür. Oyunların sosyal gelişimle birlikte dilsel, kültürel gibi pek çok alanda olumlu gelişmeye 
katkı sunduğu alan yazında yapılan çalışmalarla da dikkatlere sunulmuştur (Esen, 2008: 364-365).

Çocuklar tarafından firsat bulundukça oyunlar oynandığı görülmüştür. Çizk oyununda atış yaparken, Simit kovarken nefesini kontrol ederken, sobe oyununda saklananları ararken sobe bölgesinden uzaklaşırken saklananlardan birinin sobelemek için koştuğunda vb. oyunlarda psikomotor faaliyetler içinde bulunmakla birlikte kendi vücudunu ve gücünü tanıyıp geliştirdiği gözlemlenmiştir.

Nitekim 'Çocuk Gelişiminde Oyunun Önemi', (2015) adlı makalede de bu tespitlerde bulunulmuştur. Yine çocuğu sosyal, fiziksel, zihinsel ve psikolojik gibi açılardan geliştirdiğini söyleyen Erdem (2019: 182-183) geleneksel oyunların yok olduğu veya sadece hafizalarda kaldığı sonucuna varmıştır. İbiş ve Aktuğ (2018) fiziksel gelişime katkısı olan oyunların ayrıca dikkat gelişimine de katkılarının olduğunu ifade etmişlerdir.

Asan (2011), çalışmasında masa tenisi egzersizi ile dikkat arasında pozitif bir ilişkiden söz etmiştir. $\mathrm{Bu}$ açıdan bakıldığında çalışmamızla çelişmeyen aksine çalışmamızı destekleyen benzer sonuçlar elde edilmiştir.

Çocuk kitaplarında yer verilen çocuk oyunlarının çocukların oyun gelişimine uygun bir şekilde hazırlanmasının hem yazarların hem de resimleyenlerin dikkat etmeleri gereken önemli bir konu olduğu ve bununu çocukları her açıdan ilgilendirdiğine (Toran ve Dilek, 2017) dikkat çekilmektedir. Devamında çocukların bu dönemde hareket ve tekrara dayalı motor becerilerini içeren oyun türlerinden ziyade yaratıcılığa, hayal gücüne, esneklik ve sembolik estetiğe dayalı oyunları oynadıkları, dolayısıyla çocuklara sunulan kitapların da bu yönden çocukları desteklemesi gerektiği ile ilgili yapılan araştırmalara (Massey, 2013; Walker, Gopnik, \& Ganea 2015) değinerek konunu öneminden bahsetmiştir.

Çocuk oyunlarının bir kültür aktarıcısı olduğu, ödül ve cezaları kabul ettirdiği, hayata hazırlayıp çocukların nasıl hareket etmesi gerektiğini, değerler açısından büyük katkıda bulunduğu gözlemlenmiştir. Nitekim Karğın (2018: 292293) ve Sümbüllü ile Altınışık (2016: 83-84) da bu tespitte bulunmuşlardır. Yine alanda yapılan araştırmalarda bazı oyunlarda ödül ve cezaya yer verilmezken bazılarına da yer verildiği gözlemlenmiş olup benzerlik arz etmektedir (Erdem, 2019: 182).

Winnicott Oyun ve Gerçeklik başlıklı eserinde "Bir çocuk ya da yetişkin ancak oynarken ve sadece oynarken yaratıcı olabilir ve bütün kişiliğini kullanabilir; birey de kendini ancak yaratıcı olduğunda keşfedebilir." (Winnicott, 2017: 75) gerçeğine vurguda bulunarak oyunların çocukların yaratıcılıklarına katkısı hakkında fikir vermektedir.

$\mathrm{Bu}$ açıdan bakıldığında çocuk ancak bu yolla şekillenip olgunlaşma yolunda ilerleyebilir. Nitekim Nietzsche'ye (2009) göre insandaki olgunluk; insanın çocukluğunda oynarken yaşadığı ciddiyeti bir kez daha keşfetmesi ile mümkündür. Bu da insanoğluna şu gerçeği hatırlatmaktadır: Canlı varlık oyun oynarken, doğuştan gelen bir taklit eğiliminin hükmü altındadır, bir gevşeme ihtiyacını tatmin etmektedir, hayatın ondan talep edeceği ciddi faaliyetlere hazırlık antrenmanı yapmaktadır ya da oyun insanın nefsine hâkim olmasını sağlamaktadır (Huizinga, 1995).

Buradan bakıldığında çocuk oyunları ile ilgili yapılacak çalışmalarda şu huşulara dikkat edilmesi büyük önem taşımaktadır: Toran ve Dilek (2017) çalışmalarında aktardıkları şekli ile Piaget, çocuk oyunlarını üç aşamada çocuğun zihinsel gelişimine uygun olarak ele almakta ve bu aşamalar, duyu-motor, işlem öncesi ve somut işlem dönemlerinin karşılığı olarak yer almaktadır. Piaget'nin oyun gelişini kuramı aşamaları incelendiğinde ilk aşamanın alıştırma oyunları (0-2 yaş), ikinci aşamanın sembolik oyun (2-12 yaş) ve üçüncü aşamanın ise kurallı oyun (12 ve üzeri yaş) olduğu görülmektedir. Piaget'nin oyun gelişimi kuramına göre çocukta oyun gelişimi bir evrim süreci içerisinde gelişmektedir. Bu süreç alıştırma oyunları ile başlayıp kurallı oyun aşamasına doru ilerlemekte ve kurallı oyunlar sürecin son aşaması olarak kabul edilmektedir (Nicolopoulou, 1993)

Çocukluğun biyolojik bir temeli vardır, fakat sosyal bir çevre çocukluğu başlatmadıkça ve bakıp büyütmedikçe, yani ona gereksinim duymadıkça gerçekleşmeyebilir. Eğer bir kültür, doğal olmayan, uzmanlaşmış ve karmaşık beceri ve tutumları öğrensinler diye çocuklar ile ilgili ayrım yapılmasını gerektiren bir aracın egemenliği altında olursa, o zaman çocukluk, bu veya başka bir biçimde olmak üzere ortaya çıkacak, topluma eklemlenecek ve toplumdan koparılamaz olacaktır. Eğer bir kültürün iletişim gereksinimleri, çocukların uzun süreli ayrımını gerektirmez ise, o zaman çocukluk sessiz kalır (Postman, 1995: 182).

Dünya üzerinde yapılan çalışmalara bakıldığında da son dönemlerde çocuğa ve çocuklar için etkinliklere verilen önem daha da artmaktadır. Çocuklar için özel alanlar ve etkinlikler hazırlanmaktadır. Bunun en belirgin özelliklerinden birisini Onur (2010) çalışmasında oyuna ve oyuncağa gereken önemin verilmesine yönelik önerilerini siralarken buna örnek olarak dünyada sayısı hızla artan oyuncak müzelerini göstermektedir.

Batı toplumlarında oyunun bir yandan idealleştirilirken öbür yandan da evcilleştirildiği gerçeği pek çok yerde tartışma konusu yapılmıştır. 1999'da Tokyo'da yapılan uluslararası konferansa Amerika'dan katılan B.A. Wright'ın gözlemi de bu noktadaydı: "Oyunun sağlıklı ve mutlu çocuklara katkısının açık olmasına karşın, oyunun göreceli önemi Amerikan toplumunda çoğu zaman ihmal edilmiştir. Uzun süreli dinsel inançlarla dolmuş güçlü bir iş ahlakı Amerikalıların iş ve oyun karşısındaki tutumlarında hâlâ egemendir. Çocuklar formel okullara gitgide daha erkenden sokulmaktadırlar. Bu okul öncesi kurumlardaki etkinliklerin çoğu oyuna yöneltilmiş olmakla birlikte, bunlar çoğu zaman yapılandırılmış olan, oyunun yapılandırılmamış biçimlerinin büyüme potansiyeline de izin vermeyen etkinliklerdir." Batı ülkelerinde çocuk oyunları konusunda bütün tartışma yukarıdan beri söz ettiğimiz bu çelişki üzerinde yoğunlaşıyor. Bu çelişkiyi çocukları tümüyle kontrol etmek, sonunda iyi tüketiciler yapmak isteyen sistemlerin yarattığı ileri sürülüyor. Akademik hırs ve rekabet, ne pahasına olursa olsun başarı kazanma isteği, eve kapanma zorunluluğu gibi diğer etkenler de denetimli oyunla birleşince ortaya "yalıtılmış" bir çocukluk çıkıyor (Onur ve Güney, 2004).

Çocuklar, göremeyeceğimiz bir zamana gönderdiğimiz canlı mesajlardır. Biyolojik açıdan herhangi bir kültürün kendisini yeniden üretme gereksinimini unutması tasavvur edilemez. Fakat bir kültürün toplumsal açıdan çocukluk fikrine sahip olmaksızın var olması oldukça muhtemeldir. Bebekliğin tersine çocukluk, biyolojik bir kategori değil, toplumsal bir kurgu (Postman, 1995: 7) olduğu gerçeği unutulmamalıdır. 
$\mathrm{Bu}$ gerçekten hareketle oyun denilince akla ilk gelen çocukluk oluyor. Ancak büyüklerin bu konuda eksik düşündükleri ve oyunun bir ihtiyaç olduğu gerçeğini unutmaları gerektiği vurgulanmakta ve oyun kavramının çok geniş kapsamlı olduğu dikkate sunulmaktadır. Çünkü çocuklarla oynanan oyunlar aslında büyüklerin de kendi oyun ihtiyaçlarını karşıladığına (Erdoğan, 2020) dikkat çekilmektedir.

Tüm bunlardan hareketle çocuklar her ne kadar toplumsal etkilerle şekillenip olgunlaştığı vurgulansa da tam tersi durumda söz konusu olabilmektedir. Yani çocuklar da bazı konularda oyunları ile topluma etki edebildikleri dile getirilmektedir. Bu konuda yapılan çalışmada Ankara köylerinde çocuklar o sene hangi oyunu oynarsa o yıl onunla ilgili işlerin çok olacağı inancına rastlanmaktadır. Mesela çocuklar kuyu kazarak oynarsa o sene bolluk olur, ekin kuyuları kazılırmış (And, 2016) şeklinde bir inanış söz konusudur.

Mardin geleneksel çocuk oyunlarının derlenip gelecek kuşaklara aktarılması ve bireyin gelişimine olan etkisinin incelendiği çalışmamızda geleneksel çocuk oyunlarının köylerde aktif olarak oynandığı, bilgisayar oyunlarının olmayıp uygun ortamın olduğu yerlerde dikkatleri kendine çektiği görülmekle birlikte birçok oyunun sadece akıllarda kalıp oynanmadığı görüldüğünden dolayı adı geçen oyunların gelecek kuşaklara aktarılması açısından önemli olduğu görülmüştür. Bu sebepten dolayı daha ayrıntılı bir çalışmayla her bir yöreye ait çocuk oyunlarının bir an önce derlenmesine gerek duyulmaktadır.

\section{3. Öneriler}

$\mathrm{Bu}$ araştırmanın sonucunda şu önerilerde bulunulabilir:

1. Geleneksel çocuk oyunlarının iyi, bilgisayar oyunlarının kötü olduğu algısının yetersiz bir değerlendirme olduğu gerçeği göz ardı edilmemelidir

2. Geleneksel çocuk oyunlarının oynanabilmesi için uygun zaman ve mekânın gerek aile gerek devlet tarafindan çocuklara sağlanması gerekmektedir.

3. Çocuk oyunlarının fiziksel, zihinsel, sosyal, dil gelişimi gibi birçok gelişim alanını etkilediğinden dolayı bu alanla ilgili daha ayrıntılı çalışmaların yapılması gerekmektedir.

4. Henüz unutulmamışken çocuk oyunlarının daha kapsamlı bir şekilde derlenip kayıt altına alınması büyük önem taşımaktadır.

\section{Kaynakça}

Anılan, H., Girmen, P., Öztürk A. \& Koçkar M. T. (2003, Ekim). Geleneksel çocuk oyunlarının eğitimsel değeri. OMEP Dünya Konsey Toplantısı ve Konferansı, Aydın.

And, M. (2016). Oyun ve bügü /Türk kültüründe oyun kavramı, İstanbul: Yapı Kredi Yayınları

Baykoç Dönmez, N. (1992). Oyun kitabı. İstanbul: Esin Yayınevi,
Bateson, P \& P Martin, P. (2014). Oyun, oyunbazlık, yaratıcılık ve inovasyon, (Çev. Songül Kırgezen), Ayrıntı Yayınlar1,

Büyüköztürk Ş., Çakmak E. K., Akgün Özcan E., Karadeniz Ş., ve Demirel F. (2019). Bilimsel araştırma yöntemleri. Ankara: Pegem Akademi

Cirhinlioğlu, F. G. (2001). Çocuk ruh sağlığı ve gelişimi. Ankara: Nobel Yayıncılık.

Çakırer Özservet, Y. (2015). Geleneksel çocuk oyunları için sokak temelli geleneksel oyun alanlarının yeniden keşfi. I. Uluslararası Türk Dünyası Çocuk Oyun ve Oyuncakları Kurultayı. 14-15 Mayıs, 2015. Eskişehir.

Çok, F., Artar, M., Şener, T., \& Bağlı M. T. (2004). Kentlerdeki açık alanlarda çocuk oyunları: Ankara Örneği. İçinde B. Onur \& N. Güney (Ed.), Türkiye'de çocuk oyunları: Araştırmalar (s. 16-28) Ankara: Kök Yayıncilik

Çolak, M. (2015). Adana geleneksel çocuk oyunları. Yayımlanmamış Yüksek Lisans Tezi. Niğde: Niğde Üniversitesi.

Dursun, Y. (2014). Oyun ontolojisi, Doğu Batı Yayınları

D. W. Winnicott, (2019). Oyun ve gerçeklik, (Çev. Tuncay Birkan), Metis Yayınları,

Erdem, N. A. (2019). Artvin'de çocuk oyunları (Derleme, inceleme, tasnif). Yayımlanmamış Yüksek Lisans Tezi. Artvin: Çoruh Üniversitesi.

Erden, Ş. ve Alisinanoğlu, F. (2002). Anaokullarına devam eden çocukların ebeveynlerinin çocuk oyun ve oyuncakları hakkındaki görüşlerinin incelenmesi. Cukurova Üniversitesi Eğitim Fakültesi Dergisi, 2 (22), 42-49

Erdoğan, E. (2020). Saklambosi, İstanbul: İz Yayıncılık

Esen, M. A. (2008). Geleneksel çocuk oyunlarının eğitimsel değeri ve unutulmaya yüz tutmuş Ahıska oyunları. Uludă̆ Üniversitesi Eğitim Fakültesi Dergisi, 21 (2), 357-367

Fink, E. (2015). Bir dünya sembolü olarak oyun, İstanbul: Dost Kitabevi,

Gültat, B. Sündük, B., \& Ayyıldız S. (2015). Çocuk gelişiminde oyunun önemi, https://www.academia.Edu/35922977/\%C3\%87ocuk_G eli\%C5\%9Fiminde_oyunun_\%C3\%96nemi

Huizinga, J. (1995). Homo Ludens: Oyunun toplumsal işlevi üzerine bir deneme, (Çev. Mehmet Ali Kılıçbay), Ayrıntı Yayınları.

İbiş S. \& Aktuğ Z. B. (2018). Effects of sports on the attention level and academic success in children. Educational Research and Reviews,13(3), 106-110.

Kara, U, Y. (2014). Kimlik Oyunu: Video Oyunları, Yeni Medya ve Kimlik, Ístanbul: İletişim Yayınları,

Karğın, D. (2018). Şanlıurfa ili ve çevresi çocuk oyunları. Yayımlanmamış Yüksek Lisans Tezi. Ardahan: Ardahan Üniversitesi 
Mutlu, E. C. (1999). Uluslararası işletmecilik. İstanbul: Beta Basım Yayım

Onur, B. (2010). Oyuncaklı dünya: Oyuncă̆ın toplumsal tarihi, İmge Kitabevi,

Onur, B., \& Güney, N. (2004). Türkiye'de çocuk oyunlarl: araştırmalar. Ankara: Ankara Üniversitesi Çocuk Kültürü Araştırma ve Uygulama Merkezi Yayınları no: 12

Postman, N. (1995). Çocukluğun yok oluşu, (Çev. Kemal İnal), İmge Kitabevi Yayınları

Selçuk, K. (2019). Oyunun Çocuk Gelişimi Üzerindeki Önemi ve Açık Parkların Tasarım Kriterleri Bakımından Incelenmesi. Yayımlanmamış Yüksek Lisans Tezi. Adana: Çukurova Üniversitesi

Sülün, M. (2019). Çocuğun gelişmesinde oyun alanlarının rolü ve mekânsal gereklilikler: Ankara örneğinde özel ve kamusal çocuk oyun alanlarl üzerinden bir inceleme. Yayımlanmamış Yüksek Lisans Tezi. İstanbul:b Yıldız Teknik Üniversitesi
Sümbüllü, Y. Z., \& Altınışık M. E. (2016). Geleneksel çocuk oyunlarının değerler eğitimi açısından önemi. ETÜ Sosyal Bilimler Enstitüsü Dergisi, 1 / 2, 73-85.

Sahin, S. (2016). Afganistan Türkmenlerinin kültüründe çocuk oyunları, Selçuk Üniversitesi Türkiyat Araştırmaları Dergisi, Güz 2016, (40): 261-271

Toran, M., \& Dilek, A. (2017). Çocuklar ve kitaplar: Piaget'nin oyun kuramına göre bir değerlendirme. Yaşadıkça Eğitim, Cilt 31, Sayı 1, s. 41-54.

Yalçın Irmak, A. \& Erdoğan, S. (2016). Ergen ve genç erişkinlerde dijital oyun bağımlılığı: Güncel bir bakış. Türk Psikiyatri Dergisi 27(2), 128-37.

Yeşil, S. (2013). Kültür ve kültürel farklılıklar: liderlik açısından teorik bir değerlendirme. Elektronik Sosyal Bilimler Dergisi, 12 (44), 52-81.

\section{Kaynak Kişiler}

$\begin{array}{lcc}\text { Soyadı-Adı } & \text { Doğum Yeri } & \text { Öğrenim Durumu } \\ \text { KK1. ATSIZ, Ali } & \text { Mazıdağı } & \text { Ön Lisans Mezunu } \\ \text { KK2. İLEK, Mazlum } & \text { Mazıdağı } & \text { Lisans Mezunu } \\ \text { KK3. EKINNCI, Yakup } & \text { Mazıdağı } & \text { Lisans Öğrencisi } \\ \text { KK4. GAYIR, Hatip } & \text { Mazıdağı } & \text { Ön Lisans Mezunu } \\ \text { KK5. DAYAN, Büşra } & \text { Derik } & \text { Ortaokul Öğrencisi } \\ \text { KK6. GÜNDÜZ, Ömer } & \text { Midyat } & \text { Lisans Öğrencisi } \\ \text { KK7. TAN, Merve } & \text { Derik } & \text { Ortaokul Öğrencisi } \\ \text { KK8. ABA, Sedat } & \text { Mazıdağı } & \text { Lisans Mezun } \\ \text { KK9.COŞKUN, Ömer } & \text { Mazıdağı } & \text { Lisans Mezunu } \\ \text { KK10. EKİNCI, Ahmet } & \text { Derik } & \text { Lise Mezunu } \\ \text { KK11. ELİTAŞ, Beyza } & \text { Mazıdağı } & \text { Ortaokul Öğrencisi } \\ \text { KK12.DERİN, Beyaz } & \text { Derik } & \text { Ortaokul Öğrencisi } \\ \text { KK13.ATAŞ, Zeynep } & \text { Derik } & \text { Ortaokul Öğrencisi } \\ \text { KK14. YAŞAR, Sedef } & \text { Derik } & \text { Ortaokul Öğrencisi } \\ \text { KK15. KIZTANRI, Kadir } & \text { Mazıdağ1 } & \text { Ön Lisans Mezunu }\end{array}$




\section{Extended Abstract}

Mankind has always endeavored to produce and open new areas for himself in the process from his creation until today. Consciously or unconsciously, he has always continued this effort. He continued this effort, sometimes at the cost of his life. Especially when looking at the efforts towards social life, the title of culture draws attention. Because culture includes many fields. Many aspects from economy to art, from entertainment to life are included in the concept of culture. From this point of view, when children's games are considered as a part of the culture, as a transmitter and a factor that prepares children for life, its close relationship with culture is striking, but its relationship with folklore also draws attention. From this point of view, it can be said that one of the important fields of study of folklore is children's games. It was conducted using the qualitative research methods, document analysis and semi-structured interview technique. Thus, the field research on folk culture products was used and the products obtained were subjected to document examination. Interviews were held and compilations were made in the classroom, hallway, school yard, workplace, coffeehouse, and neighborhood. During the compilation, in addition to taking various notes, how the game was played was determined in detail, and it was determined through observations which contributed to the development of the field.

As a result of interviews with 9 men and 6 women, 20 games were compiled, 13 of them were analyzed under the titles "Games Played with Any Object" and 7 "Games Not Played with Any Object". It was observed that 6 of the source persons interviewed were not involved in any level of education. The games that were played but not named were either named using a term related to the game or a suggestion was received from the compiled person and name.

The games that were played but not named were either named using a term related to the game or a suggestion was received from the compiled person and name. The collected games were handled as given by the sources, and the interview was conducted in a conversation atmosphere. After the games were organized and transferred to the computer environment, the benefit to the development of the individual was examined in line with field scanning and expert opinion and necessary determinations were made.

Mardin children's games, which were obtained by interviewing and interviewing resource persons, were classified as children's games played with any vehicle and children's games not played with any vehicle. In the study without discrimination, it was concluded that children's games are generally related to culture, folklore, child development and that games contribute to the development of individuals.

Another result reached about the games is as follows: In the interviews with the resource persons, it was observed that the games were played either at school or in large places. It is seen that the reasons such as the decrease in playgrounds with the increase of construction everywhere, the increase of computer games with the development of technology, the shrinkage of the playgrounds with the development of the apartment culture, the decrease in trust in neighbors, the increase in the number of exams and the increase of competition and the child not living in childhood are also seen to have an effect on children's games.

Complying with what the person said in the game "Renk Tutmaca (Color Retention)", hiding without leaving the specified areas in the game "Sobe (Hide and Seek)", It has been concluded that those caught in the game of " Amerika (America)" help it and catch the others, obey the punishments and do what is necessary in the game of "Nişan (Put a Bull's Eye)", as well as social development and positive development in many areas such as linguistic and cultural.

It positively affects the psycho-motor development area in games that try to avoid getting caught by it. Since it is a game that positively affects mental development in "Rêz" game, it is seen that strategy is important in this game like other games.

As we tried to explain, it is seen that those who play traditional children's games positively affect the psychomotor, cultural, social, linguistic, physical and mental development areas. This gives the result that families should make an effort to ensure that schools should engage in activities that support playing games.

While shooting in the "Çizk" game, controlling his breath while firing a bagel, searching for what is hiding in the sobe game, when one of the hiding runs to sobere, etc. Although he does psycho-motor activities in games, it has been observed that he recognizes and develops his own body and strength.

As a result of this research, the following suggestions can be made:

1. It should not be overlooked that the perception that traditional children's games are good and computer games are bad is an inadequate evaluation.

2. In order to play traditional children's games, children should be provided with the appropriate time and place by both the family and the state.

3. Since children's games affect many developmental areas such as physical, mental, social and language development, more detailed studies are required in this area.

4. It is of great importance that children's games are compiled and recorded in a more comprehensive way, while they have not been forgotten yet. 